\title{
Counseling ethics education: teaching and learning development reformation
}

\begin{abstract}
Counseling ethics competency is an essential part of counselor identity development, and counseling ethics education is one major component of knowledge acquisition in counseling profession training standards. The chapter disseminates comprehension on the current trend in teaching and learning counseling ethics education in more effective ways based on the literature than research conducted by the profound counseling researchers, globally. Teaching and learning counseling ethics education undertakings are more than just content acquirement from textbooks; it encompasses salient elements such as safety, connection, respect, engagement, accountability, reinforcement, application, personalization, and teamwork. The chapter stances education foundation as the avenue to gaining knowledge, skills, and basic foundation in learning counseling ethics; education integration as the catalyst to understanding course content and application using experiential activities and hands-on orientation; and education application as the platform to utilizing the code of ethics across courses throughout the training program. The chapter also poses recommendations for counselor educators and counseling students toward enhanced ideas and more effective methods in teaching and learning counseling ethics education to strengthen the educational institutions in meeting the social demands and global challenges.
\end{abstract}

Keyword: Classroom environment; Ethic education; Counseling professional; Counseling student 